\title{
A prospective study of calorimetric estimation of blood loss in TURP cases
}

\author{
Kirde D. ${ }^{1}$, Thorat Santosh ${ }^{2}$, Mishra S. ${ }^{3}$, Dube V.S. ${ }^{4}$ \\ ${ }^{1}$ Dr Dattatraya Kirde, Senior Resident, ${ }^{2}$ Dr Santosh Thorat, Assistant Professor, ${ }^{3}$ Dr Shivayak Mishra, Resident, ${ }^{4}$ Dr V S \\ Dube, Professor, all authors are affiliated with department of Surgery, B.J. Medical College, Pune, Maharashtra, India
}

Address for Correspondence: Dr Santosh Thorat, Assistant Professor E 21, Vishnu Sadashiv Sasoon Doctors Quarters, Opp.Old Pune Zila Parishad, Navin Mangalwar Peth, Pune 411001 (Maharashtra). Email: drsantosh308@gmail.com

\begin{abstract}
Introduction: BEP is hyperplasia of prostatic stromal epithelial cells to form discreate nodules in transitional zone of prostate. It leads to constriction of urethral opening which gives rise to associated lower urinary tract symptoms such as frequency, urgency, nocturia. Initially disease can be managed by drug treatment but eventually most of the patients require surgical management. TURP remains gold standard treatment. Blood loss during and after procedure is major problem. This study was planned to evaluate the approximate blood loss with the help of simple technique of colorimatry. Method: This study is carried out on 50 patients with BEP who underwent TURP in our institute from October 2014 and June 2015. Irrigation fluid collected during TURP, post operative day $1 \& 2$ subjected to calorimetric estimation of blood loss using Drabkin's reagent. Results: The results were suggestive of approximate average blood loss during TURP procedure as 267 $\mathrm{ml}$, post operative day 1 blood loss $98.9 \mathrm{ml}$ and post operative day 2 loss was $58.1 \mathrm{ml}$. However the average blood loss changes according to the size of prostate and duration of the procedure. Conclusion: calorimetric estimation of blood loss during and post operative period is an easy, economically feasible, quick method to guide the management of blood requirement for the patient. This can be useful in patients with BEP and bleeding diathesis.
\end{abstract}

Keywords: TURP, Colorimetric, Blood loss in TURP, Drabkin's reagent.

\section{Introduction}

Benign prostatic hyperplasia (BPH) is characterized by the hyperplasia of prostatic stromal epithelial cells to form discrete nodule in transition zone of prostate. It ultimately constricts the urethral opening and gives rise to associated lower urinary tract symptoms (LUTS) such as urgency, frequency, nocturia, incomplete bladder emptying, and weak urine stream.

Left untreated, serious complications can occur in men with $\mathrm{BPH}$, including acute urinary retention, renal insufficiency and failure, urinary tract infection, and bladder stones[1].

Manuscript Received: $05^{\text {th }}$ September 2016

Reviewed: $12^{\text {th }}$ September 2016

Author Corrected: $18^{\text {th }}$ September 2016

Accepted for Publication: $30^{\text {th }}$ September 2016
Prostatectomy procedure remains the best treatment option for the hyperplastic glands which stop responding to drug therapy. TURP has largely replaced other methods, except in case of divrticulectomy or the removal of large stones, where open operation is preferred. Nowadays, over $95 \%$ of prostatectomies are TURPs. TURP remains the gold standard method for

surgical treatment of benign prostati hyperplasia [2]. However; this surgical technique is not without problems. As the surgical target area is highly vascular, TURP leads to heavy bleeding. This study was planned to evaluate the approximate blood loss that occurs as a result of bipolar TURP procedure. The overarching goal was to evaluate the blood loss that occurs with the help of simple technique of colorimetric. 
It was also planned to find out the incidence of complications associated with bipolar TURP.

\section{Aim}

To study the average blood loss and complications which occur during TURP.

\section{Materials and Methods}

The study was conducted in a tertiary care teaching hospital .Institutional Ethical Committee permission was obtained prior to commencement of the study. We conducted this study on 50 patients of benign prostatic hypertrophy who undergone TURP surgery in our hospital between October 2014 and June 2015.

Type of Study: Descriptive, single centre study.

\section{Inclusion Criteria}

1) A patient having benign prostatic hypertrophy

2) Age more than 40 years

3) Prostatic symptoms not relieved by medical management

4) Prostate size up-to $100 \mathrm{cc}$

\section{Exclusion Criteria}

1) Patient having bleeding disorder.

2) PSA level $>4 \mathrm{ng} / \mathrm{ml}$

3) Patient with active UTI

\section{Method of Collection of Data}

1. The pre-operative data was collected including Patient's demographics, Detailed history,Comorbidities,Indication of surgery, Prostate size, (radiological estimation), Laboratory investigations including preoperative haemoglobin, Medications administered prior to surgery.

2. Intra-operative data was collected i.e. Volume of fluid collected during surgery \& Duration of the surgery.

3. Post-operative data included -

- Volume of fluid collected at the end of post-operative day $1 \& 2$

- Volume of total fluid collected at the end of $2^{\text {nd }}$ postoperative day

- Complications that occurred as a result of TURP surgery.

\section{Objectives}

A. To estimate the average blood loss that occurs after TURP by colorimetric method.

B. To evaluate the complications of TURP.

4. Using colorimetric method, the approximate blood loss was estimated in a fluid collected during surgery, at the end of post-operative day 1 and at the end of postoperative day 2. The total blood loss was estimated. The average prostate size was summarized as mean and standard deviation.

5. The average blood loss as a result of TURP was summarized as mean and standard deviation. The correlation between prostate size and blood loss as a result of TURP was found out. The incidence of complications occurring as a result of TURP surgery was noted. All statistical tests were considered significant at $\mathrm{p}<0.05$ level of significance.

Estimation of blood loss by colorimetric methodIrrigation fluid was collected during TURP, on postoperative day 1 and on post-operative day $2.10 \mathrm{ml}$ sample was taken from each of these three collections in 3 different dry, autoclaved glass containers. The samples were processed for Hb estimation by Drabkin's method.

Drabkin's method of haemoglobin estimation principle: Blood is diluted in a solution containing potassium cyanide and potassium ferricyanide. The latter converts $\mathrm{Hb}$ to methemoglobin which is converted to brownish coloured cyanmethemoglobin ( $\mathrm{HiCN}$ ) by potassium cyanide. The absorbance of the solution is then measured in a colorimeter using a yellow green filter (540 $\mathrm{nm})[3]$.

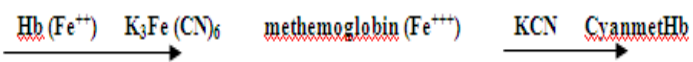

\section{Reagents utilized}

$\begin{array}{ll}\text { 1. Drabkin's Reagent } & \mathbf{1 0 0 0 ~} \mathbf{~ m L} \\ \text { Potassium Ferricyanide } & 0.60 \mathrm{mMol} / \mathrm{L} \\ \text { Sodium Cyanide } & 0.77 \mathrm{mMol} / \mathrm{L} \\ \text { Phosphate Buffer } & 1.00 \mathrm{mMol} / \mathrm{L}\end{array}$
2. Cyanmethaemoglobin Standard $10 \mathrm{~mL}$
Haemoglobin $0.06 \mathrm{Gms} / \mathrm{dL}$


(Equivalent to $15.06 \mathrm{Gms} / \mathrm{dL}$ in assay condition)

* Reagents were ready to use.

\section{Procedure}

- Colorimeter was set at green filter, i.e. $540 \mathrm{~nm}$ filter

- Blanking with distilled water was done to adjust the optical density (OD) at zero.

- Then OD of Drabkin's reagent was measured.

- This value was deducted from the OD reading of sample to nullify the effect of reagent's colour. (i.e. Reagent Blanking was done)

- In a routine method of $\mathrm{Hb}$ estimation in whole blood, 20 microL. i.e. $0.02 \mathrm{ml}$ blood sample is added to $5 \mathrm{ml}$ of Drabkin's reagent and after 5 minutes of incubation, OD is measured at $540 \mathrm{~nm}$ in colorimeter.

- In case of irrigation fluid, the concentration of $\mathrm{Hb}$ in fluid is very much diluted in comparison to whole blood.

- Due to this, the proportion of sample and reagent is taken differently while estimating $\mathrm{Hb}$ in fluid.

- For $\mathrm{Hb}$ estimation in irrigation fluid, obtained during TURP

○ $\quad 0.5 \mathrm{ml}$ Irrigation fluid was added to $3.5 \mathrm{ml}$ Drabkin's reagent

- It gave ' 8 ' as a factor for $\mathrm{Hb}$ estimation (8 times dilution)

- For $\mathrm{Hb}$ estimation in irrigation fluid, obtained on postop day 1

○ $\quad 0.5 \mathrm{ml}$ Irrigation fluid was added to $2.0 \mathrm{ml}$ Drabkin's reagent

$\mathrm{Gm} / \mathrm{dL})]$.

\section{Results}

Table-1: Age distribution of patients

\begin{tabular}{|l|c|l|l|}
\hline & Mean \pm SD & Minimum & Maximum \\
\hline Age of patients (years) & $66.67 \pm 5.6$ & 57 & 80 \\
\hline
\end{tabular}

The mean age of patients enrolled in study was $66.7 \pm 5.6$. The youngest patient was 57 years old, while the oldest was 80 years old.

Table-2: Prostate size of patients

\begin{tabular}{|l|l|l|l|}
\hline & Mean \pm SD & Minimum & Maximum \\
\hline Size of prostate $(\mathrm{cc})$ & $62.72 \pm 6.77$ & 54 & 90 \\
\hline
\end{tabular}

The prostate size of patients was averagely $62.72 \pm 6.77 \mathrm{cc}$. The minimum size reported was $54 \mathrm{cc}$, whereas the maximum reported size was $90 \mathrm{cc}$. 
Table-3: Irrigation fluid collection during surgery, on post-operative day 1 and day 2

\begin{tabular}{|c|c|c|c|}
\hline Volume of fluid (L) & Mean \pm SD & Minimum & Maximum \\
\hline During Surgery & $14.57 \pm 1.49$ & 71.8 & 14.2 \\
\hline Post-op Day 1 & $11.53 \pm 1.37$ & 4.5 & 9.0 \\
\hline Post-op Day 2 & $5.75 \pm 0.83$ & $\mathbf{2 5 . 2}$ & $\mathbf{3 8 . 9}$ \\
\hline
\end{tabular}

Irrigation fluid collected during TURP surgery was averagely $14.57 \pm 1.49$ litres. The minimum volume of fluid collected in a patient was 11.8 litres where as the maximum volume collected was 17.2 litres.

At the end of $1^{\text {st }}$ post-operative day, mean volume of fluid collected was $11.53 \pm 1.37$ litres. 7.9 litres was the minimum volume collected in a patient and 14.2 litres was the maximum volume of fluid collected in a patient.

The mean volume of irrigation fluid collected on $2^{\text {nd }}$ post-operative day was $5.75 \pm 0.83$ litres, minimum volume being 4.5 litres. The maximum volume of fluid collected was 9.0 litres in one of patients.

Table-4: Pre-operative blood $\mathrm{Hb}$

\begin{tabular}{|c|c|c|c|}
\hline & Mean \pm SD & Minimum & Maximum \\
\hline $\mathrm{Hb}(\mathrm{Gms} / \mathrm{dL})$ & $13.59 \pm 1.32$ & 10.6 & 16.0 \\
\hline
\end{tabular}

The pre-operative mean Haemoglobin concentration in study subjects was $13.59 \pm 1.32 \mathrm{Gm} / \mathrm{dL}$. The lowest Hb concentration reported was $10.6 \mathrm{Gm} / \mathrm{dL}$ whereas the highest concentration reported was $16.0 \mathrm{Gm} / \mathrm{dL}$.

Table-5: Estimated blood loss during surgery, on post-operative day 1 and 2

\begin{tabular}{|c|c|c|c|}
\hline Blood Loss (ml) & Mean \pm SD & Minimum & Maximum \\
\hline During Surgery & $266.9 \pm 42.6$ & 198.0 & 131.9 \\
\hline Post-op Day 1 & $98.8 \pm 14.8$ & 73.0 & 90.9 \\
\hline Post-op Day 2 & $58.0 \pm 16.23$ & 29.6 & 565.9 \\
\hline
\end{tabular}

The average volume of total fluid collected after TURP surgery was $31.85 \pm 3.27$ litres, the minimum volume being 25.2 litres and the maximum volume being 38.9 litres.

The average estimated blood loss during TURP surgery was $266.9 \pm 42.6 \mathrm{ml}$. The estimated minimum blood loss was 198.0 $\mathrm{ml}$, while the maximum estimated blood loss was $374.2 \mathrm{ml}$.

On the $1^{\text {st }}$ post-operative day, averagely $98.8 \pm 14.8 \mathrm{ml}$ blood loss was estimated. $73.0 \mathrm{ml}$ was the minimum detected blood loss, while $131.9 \mathrm{ml}$ was the maximum blood loss detected in a patient.

The average blood loss detected on $2^{\text {nd }}$ post-operative day was $58.0 \pm 16.23 \mathrm{ml}$. The minimum blood loss estimated was 29.6 $\mathrm{ml}$, while the maximum blood loss estimated was $90.9 \mathrm{ml}$. 
The average estimated total blood loss, resulting from TURP surgery was $423.9 \pm 68.0 \mathrm{ml}$, maximum being $565.9 \mathrm{ml}$ and minimum being $317.0 \mathrm{ml}$

Table-6: Incidence of complications

\begin{tabular}{|l|c|}
\hline Complication & $\begin{array}{c}\text { Incidence } \\
\text { Number (\%) }\end{array}$ \\
\hline TUR Syndrome & $1(2 \%)$ \\
\hline Hemorrhage & 0 \\
\hline Incontinence & $2(4 \%)$ \\
\hline Urethral Stricture & 0 \\
\hline Erectile Dysfunction & $50(100 \%)$ \\
\hline Retrograde Ejaculation & 0 \\
\hline
\end{tabular}

The overall incidence of complications was $6 \%$ in our study. 2 patients (4\%) suffered from urethral stricture, while 1 (2\%) patient developed TUR syndrome. All the patients developed retrograde ejaculation. None of the patients showed evidence of post-operative haemorrhage, incontinence, erectile dysfunction or any other significant morbidity. The major late complications are urethral strictures $(2.2-9.8 \%)$ and bladder neck contractures $(0.3-9.2 \%)$ [4].

\section{Discussion}

The prostate gland (normal weight: $20 \mathrm{~g}$ ) encircles the urethra as it emerges from the base of the bladder. It comprises glandular (secretory acini) and non-glandular (smooth muscle and fibrous tissue) components enclosed by a fibrous capsule. It has a rich blood supply and venous drainage is via the large, thin-walled sinuses adjacent to the capsule.

It is described as having four histological zones (McNeal zones): the central, peripheral, anterior (fibromuscular), and transitional (periurethral) zones. The transitional zone surrounds the proximal urethra in two pear-shaped lobes.

It comprises $5 \%$ of normal prostatic volume and is the site of BPH and also $\sim 10 \%$ of prostatic carcinomata. Twenty per cent of men aged $40 \mathrm{yr}$ have hyperplasia of the transition zone, increasing to $50 \%$ at $50 \mathrm{yr}$ and $70 \%$ at 60 yr. The hyperplastic tissue eventually encroaches on the proximal urethra, causing obstruction. The normal prostatic tissue becomes compressed against the capsule, and is often referred to as the 'surgical capsule'.

In theory blood loss during TURP can be estimated by assessing the haemoglobin concentration of discarded irrigation fluid; by measuring the electrical conductivity of discarded irrigation fluid; or in laboratory by radioactive albumin or red cell labelling techniques. Urine-strip method can be used to estimate total blood loss in irrigating fluid in patients with TUR-P operation.
This is practical and useful in immediate post-operative evaluation of blood loss to consider the need of blood transfusion [5].

Sterile water; Though sterile water has many qualities of an ideal irrigating fluid, the disadvantage is its extreme hypotonicity, causing hemolysis, dilutional hyponatremia, shock and renal failure. 1.5\% Glycine is preferred solution for TURP [6]. Blood loss and postoperative complications associated with transurethral resection of the prostate after pretreatment with dutasteride results in reduced blood loss compared with placebo controls [7]. Patients lose between 2.4 and $4.6 \mathrm{ml}$ of blood per minute of resection whichever anaesthetic technique is used [8].

Ahyai et al in 2010 did a meta-analysis of twenty-seven publications involving 20 contemporary RCTs published between 2005 and 2009 with an overall sample size of 954 TURP patients [9]. Acute urinary retention (AUR), clot retention, recurrent haematuria, and urinary tract infections (UTI) or fever were the most frequently reported adverse events after TURP.

Major drawbacks of contemporary TURP remain intraoperative and perioperative complications. The analyses demonstrated that the diversity of possible complications after TURP lead to an increased cumulative risk of adverse events. Most relevant complications included urethral stricture (4.1\%; range: $0-21)$, bladder neck 
stenosis (2\%; range: $0-21)$ bleeding requiring blood transfusion (2\%; range: $0-9)$, TUR syndrome $(0.8 \%$; range: $0-5)$, AUR (4.5\%; range: $0-13.3)$, clot retention (4.9\%; range: $0-39$ ), and UTI (4.1\%; range: $0-22$ ). Indeed, in their comparative analysis, TURP was associated with the highest risk of bleeding with subsequent need for blood transfusion and remained the only procedure still harbouring the risk of documented TUR syndrome.

The wide range of severe complications suggested that TURP-related adverse events are multifactorial, with prostate size and surgical experience probably having the greatest impact. In contrast, their analysis demonstrated that the overall morbidity of TURP was not statistically significantly different compared to minimally invasive procedures[10].

Factors associated with excessive bleeding include a large gland, extensive resection $(>40-60 \mathrm{~g}$ of prostate chippings), coexisting infection, prolonged surgery ( $>1 \mathrm{~h})$, and the presence of a preoperative urinary catheter. The most practical way to quantify blood loss during TURP is by measuring $\mathrm{Hb}$ in the irrigating fluid [5].

The novel 51Cr RBCs labelling method allowed evaluating blood loss not only during the surgical procedure but also during the postoperative period, on average, blood loss from the procedure until postoperative day 3 was more than $500 \mathrm{~mL}$, which is larger than previously reported amounts as measured by other methods.

Because significant blood loss might occur during the postoperative period, the $51 \mathrm{Cr}$ method should be used to measure blood loss when evaluating new emerging techniques to manage $\mathrm{BPH}[11]$.

The extend of blood loss associated with TURP is multifactorial and it is impossible to measure the effect of single factor while controlling other factors some of the factors such as local vascularity are impossible to measure.

Of the measured factors weight of the resected prostate tissue is clearly the most important and its assessment should help in anticipating blood loss rationalizing the cross matching [12].

\section{Conclusions}

1. Colorimetric method of blood loss estimation during TURP is an cost effective easy and quick method to guide the requirement blood transfusion during intra operative and post operative period.

2. Estimation of average blood loss for given set of patient at TURP helps in formulation of hospital policy for pre operative optimisation of the patient.

3. High risk cases such as patients with deranged coagulation profile and bleeding diathesis such as thalesemia, sickle cell anaemia, haemophilia etc who are at high risk of bleeding during TURP; Colorimetric method of blood loss estimation would be an vital tool to guide the transfusion.

4. In developing countries such as India this cost effective \& easy method can be a routine guide for management of blood loss.

Conflict of interest: None declared.

Funding: Nil, Permission from IRB: Yes

\section{References}

1. Schorn MN. Measurement of blood loss: review of the literature. J Midwifery Womens Health [Internet]. 2010;55(1):20-7.

2. Shrestha BM, Prasopshanti K, Matanhelia SS, Peeling WB. Blood loss during and after transurethral resection of prostate: a prospective study. Kathmandu Univ Med J (KUMJ) [Internet]. 2008 Apr 9;6(23):329-34.

3. Ohta N, Robertson AR. Colorimetry: Fundamentals and Applications. Colorimetry: Fundamentals and Applications. 2006. 1-334 p.

4. Rassweiler J, Teber D, Kuntz R, Hofmann R. Complications of Transurethral Resection of the Prostate (TURP)-Incidence, Management, and Prevention. Eur Urol. 2006;50(5):969-80.

5. Ungjaroenwathana $\mathrm{W}$, Bunyaratavej C, Tosukhowong P, Dissayabutra T. Estimation of blood loss in transurethral resection of prostate (TUR-P) by urine-strip. J Med Assoc Thai. 2007 Nov;90(11):2409-15.

6. Ekengren J, Hahn RG. Blood loss during transurethral resection of the prostate as measured with the HemoCue photometer. Scand J Urol Nephrol 1993; 27: 501-7 
7. Hahn, R. G., Fagerström, T., Tammela, T. L.J., Van Vierssen Trip, O., Beisland, H. O., Duggan, A. and Morrill, B. (2007), Blood loss and postoperative complications associated with transurethral resection of the prostate after pretreatment with dutasteride. BJU International, 99: 587-594. doi:10.1111/j.1464410X.2006.06619.x

8. Malhotra V, Diwan S. Anesthesia and the renal and genitourinary systems. In: Miller RD, editor. Anesthesia. 5th Edn. Philadelphia: Churchill Livingstone; 2000. p. 1947-9.

9. Ahyai SA, Gilling P, Kaplan SA, Kuntz RM, Madersbacher S, Montorsi F, et al. Meta-analysis of functional outcomes and complications following transurethral procedures for lower urinary tract symptoms resulting from benign prostatic enlargement. Eur Urol [Internet]. 2010;58(3):384-97.
10. Moorthy H K, Philip S. TURP syndrome - current concepts in the pathophysiology and management. Indian J Urol 2001;17:97-102

11. Descazeaud A, Azzousi AR, Ballereau C, Bruyere F, Robert G, Delongchamps NB,Devonec M, Dumonceau O, Fourmarier M, Saussine C, Berger J, de la Taille A,Haillot O; Committee for Lower Urinary Tract Symptoms of the French Association of Urology. Blood loss during transurethral resection of the prostate as measured by the chromium-51 method. J Endourol. 2010 Nov;24 (11):1813-6. doi:10.1089/end.2010.0174.

12. KIROLLOS, M.M. and CAMPBELL, N. (1997), Factors influencing blood loss in transurethral resection of the prostate (TURP): auditing TURP. British Journal of Urology, $\quad 80$ : 111-115. doi:10.1046/j.1464410X.1997.00253.x

\section{How to cite this article?}

Kirde D., Thorat Santosh, Mishra S., Dube V.S. A prospective study of calorimetric estimation of blood loss in TURP cases. Int J surg Orthopedics 2016;2(3):42-48.doi: 10.17511/ijoso.2016.i03.04 